\section{Successful treatment of a large choledochal inflammatory polyp in a patient with cutaneous neurofibromatosis}

A 48-year-old woman was admitted to the hospital with a 1-month history of dyspeptic complaints and right upper quadrant pain. She had a 20-year history of cutaneous neurofibromatosis ( $\bullet$ Fig. 1 a). Vital signs were within normal limits. Physical examination revealed a distended abdomen with no palpable mass.

Blood test results were as follows: white cell count $8410 / \mathrm{mm}^{3}$, hemoglobin level $10.4 \mathrm{~g} / \mathrm{dL}$, aspartate aminotransferase $85 \mathrm{U} / \mathrm{L}$, alanine aminotransferase $58 \mathrm{U} / \mathrm{L}$, alkaline phosphatase $168 \mathrm{U} / \mathrm{L}$, gamma-glutamyltransferase $306 \mathrm{U} / \mathrm{L}$, total bilirubin $0.7 \mathrm{mg} / \mathrm{dl}$.

Hepatobiliary ultrasonography revealed a normal liver with no focal lesion. The intrahepatic duct and common bile duct (CBD) were dilated; the CBD was $12 \mathrm{~mm}$ in diameter. Endoscopic retrograde cholangiopancreatography (ERCP) showed the dilated intrahepatic duct and CBD. Dilatation was more prominent in the upper two-thirds of the CBD. In addition, on fluoroscopy there was an opacity suggestive of a stone in the distal CBD. Following sphincterotomy and pulling a balloon catheter through the CBD to search for a possible lesion or stone, a choledochal polyp of about $2 \mathrm{~cm}$ in diameter prolapsed into the duodenum ( Fig.1b). Polypec- tomy was performed using a standard snare polypectomy catheter. Histopathology of the choledochal polyp sample showed an inflammatory process.

The gastrointestinal manifestations of neurofibromatosis type 1 include diffuse intestinal neurofibromatosis, neurofibroma, gastrointestinal stromal tumor, ganglioneuromatosis, gangliocytic paraganglioma, periampullary somatostatinoma, periampullary carcinoids, and adenocarcinoma at different gastrointestinal sites; inflammatory polyps are also gastrointestinal manifestations of this disorder [1,2]. However, there is no information regarding the course of choledochal polyps in patients with neurofibromatosis. To the best of our knowledge, this is the first reported case of a choledochal polyp in a patient with neurofibromatosis. Choledochal polyps may obstruct the biliary tract and this obstruction may lead to jaundice, cholangitis, and acute pancreatitis. Treatment involves removing the polyp, especially those located in the distal CBD, using ERCP, and thus avoiding emergency surgery.

\section{Endoscopy_UCTN_Code_CCL_1AF_2AF}

\section{Competing interests: None}

Fatih Karaahmet ${ }^{1}$, Sahin Coban', Omer Basar², Osman Yuksel ${ }^{2}$

${ }^{1}$ Department of Gastroenterology, Dıskapı Yıldırım Beyazıt Educational and Research Hospital, Ankara, Turkey

2 Department of Gastroenterology, Hacettepe University Medical School, Ankara, Turkey

\section{References}

1 Agaimy A, Schaefer IM, Kotzina $L$ et al. Juvenile-like (inflammatory/hyperplastic) mucosal polyps of the gastrointestinal tract in neurofibromatosis type 1 . Histopathology 2013. doi: 10.1111 /his. 12325

2 Agaimy A, Vassos N, Croner RS. Gastrointestinal manifestations of neurofibromatosis type 1 (Recklinghausen's disease): clinicopathological spectrum with pathogenetic considerations. Int J Clin Exp Pathol 2012; 5: $852-862$

\section{Bibliography}

DOI http://dx.doi.org/

10.1055/s-0034-1364882

Endoscopy 2014; 46: E113

(c) Georg Thieme Verlag KG

Stuttgart · New York

ISSN 0013-726X

\section{Corresponding author}

\section{Fatih Karaahmet, MD}

Department of Gastroenterology

Dışkapı Yıldırım Beyazıt Educational

and Research Hospital

06080 Altındag

Ankara

Turkey

Fax: +90-312-3186690

fatih_ares@yahoo.com.tr

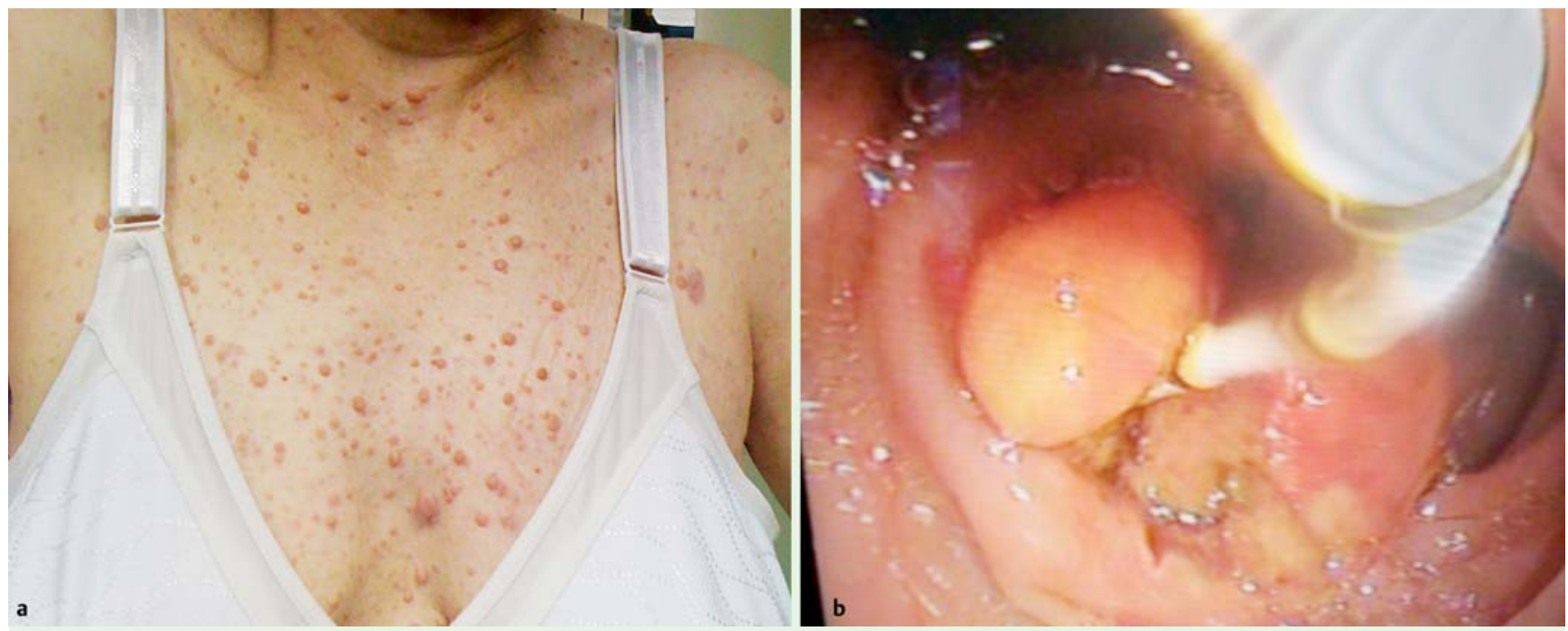

Fig. 1 Patient with cutaneous neurofibromatosis and a large choledochal inflammatory polyp. a Soft pedunculated neurofibromas are shown on the front of the patient. $\mathbf{b}$ After performing endoscopic sphincterectomy during endoscopic retrograde cholangiopancreatography, a choledochal polyp of about $2 \mathrm{~cm}$ in diameter prolapsed into the duodenum. 